\title{
Retraction Note: Psoriasin (S100A7) is a novel biomarker for lung squamous cell carcinoma in humans
}

Guijuan Liu', Qiang Wu², Guilan Liư ${ }^{3}$ Xueying Song ${ }^{4}$ and Jihong Zhang ${ }^{2^{*}}$

\section{Retraction to: Cancer Cell International (2015) 15:18 DOI 10.1186/s12935-014-0154-0}

The editors are retracting this article [1] as it has been previously published in the International Journal of Clinical and Experimental Pathology [2] and it is therefore a redundant publication. The authors could not be reached by the journal for comment on the retraction.

\begin{abstract}
Author details
1 Department of Cytology Laboratory, People's Hospital of Linyi, Linyi 276300, Shandong, China. ${ }^{2}$ Department of Nursing, People's Hospital of Yinan, Linyi 276300, Shandong, China. ${ }^{3}$ Department of Nursing, People's Hospital of Yinan, Linyi 276300, Shandong, China. ${ }^{4}$ Department of Thoracic Surgery, the People's Hospital of Rizhao, Rizhao, China.
\end{abstract}

The online version of the original article can be found under doi:10.1186/s12935-014-0154-0.

Received: 20 May 2016 Accepted: 20 May 2016

Published online: 31 May 2016

\section{References}

1. Liu G, Wu Q, Liu G, Song X, Zhang J. Psoriasin (S100A7) is a novel biomarker for lung squamous cell carcinoma in humans. Cancer Cell Int. 2015;15:18.

2. Liu G, Wu Q, Liu G, Song X, Zhang J. Knockdown of S100A7 reduces lung squamous cell carcinoma cell growth in vitro and in vivo. Int J Clin Exp Pathol. 2014;7(11):8279-89.

\footnotetext{
*Correspondence: zjhchina@sohu.com

${ }^{2}$ Department of Nursing, People's Hospital of Yinan, Linyi 276300,

Shandong, China

Full list of author information is available at the end of the article
} 